\title{
COMPARISON OF VARIOUS PROCEDURES FOR DETERMINING SUCROSE AND INULIN SPACE IN THE DOG ${ }^{1}$
}

\author{
By H. L. WHITE AND DORIS ROLF \\ (From the Department of Physiology, Washington University School of Medicine, \\ St. Louis, Mo.)
}

(Submitted for publication July 16, 1957; accepted September 5, 1957)

Seven types of procedures have been used for determining volume of distribution (space) as an estimate of extracellular fluid (ECF). These are: (a) infusion-recovery, with infusion continuing until equilibration (as indicated by constant plasma level and by failure of further infusion to change space) is achieved (1); (b) calibrated infusion continuing until constant space is achieved (2) ; (c) injection-extrapolation, i.e., extrapolation of falling plasma curve to zero time following a single injection in intact (3) or nephrectomized (4) subjects; (d) simple dilution spaces following a single injection as recovered minus excreted/ plasma level (5), or as injected minus excreted/ plasma level $(6,7)$; (e) renal clearance/slope, i.e., following a single injection of substances which are completely recovered in the urine (renal clearance equals total clearance) and whose falling plasma curve is a straight semilog line, as renal clearance in a period/change in natural logarithm of plasma level in that period (8); (f) total clearance/slope, i.e., following a calibrated infusion permitting calculation of total clearance, as total clearance/change in the natural logarithm of plasma level (9) ; (g) differential clearance, as amount excreted in a period/change in plasma level in that period, following a single injection (10).

With procedure (a), using a substance previously shown to be completely recovered, the space is calculated as amount recovered following termination of infusion/concentration in plasma water (ECF) shortly before termination. Equilibration is hastened by a priming injection. With procedure (b) a completely recoverable substance is infused without priming. Amount present in subject at time $t$ is taken as amount infused minus amount excreted up to time $t$. This is divided by concentration in plasma water (ECF) to get

1 Aided by grant No. A-92 C6, National Institutes of Health, United States Public Health Service. space at time t. Equilibration of sucrose between plasma and ECF is practically achieved even while plasma level is still rising slowly, as is indicated by constancy of successive space values. Rate of infusion must be controlled with great accuracy. In procedure (a) infusion rate need not be accurately known, and a 5 per cent error in recovered amount introduces only a 5 per cent error in space, but a 5 per cent error in infusion rate in procedure (b) may cause an error of 8 per cent in space at 90 minutes, the error increasing with time and being greater the higher the subject's clearance. It is possible, but not easy, to keep the infusion rate error below 5 per cent.

Procedure (c) in intact subjects depends on the precarious assumption that after a single injection equilibration between plasma and some reproducible compartments of total ECF exists so long as the rapidly falling plasma curve follows a straight semilog line. The amount injected is divided by the zero time extrapolated plasma (ECF) level to get space. In practice, the falling plasma curve frequently fails to follow a straight semilog line. Procedure (c) in nephrectomized subjects is on a much sounder basis. Cell entry and metabolic destruction, which are known to occur with both inulin and sucrose $(11,12)$, are allowed for by the extrapolation procedure, and there is no significant error (inulin or sucrose) in taking single (simple dilution) values at one hour in rats and at one and a half to two hours in dogs. At this time equilibration between plasma and some reproducible compartments of ECF is practically achieved, as shown by the very slowly falling straight semilog line of plasma levels, while cell entry and destruction are still negligible.

Procedure (d) for simple dilution spaces as originally employed $(6,7)$ is subject to errors of two kinds. The first is represented by whatever error is contained in the assumption that equilibration between plasma and ECF can occur with 
a rapidly falling plasma level. The second is because with progressive destruction, even of only a few per cent an hour, cumulative and rapidly increasing percentage errors appear in the dividend presumed to represent the amount remaining in the subject, thus yielding erroneously high space values which increase with time. The attempt to circumvent this difficulty (5), by calculating space as total recovered minus excreted up to time $t /$ plasma level at time $t$, depends on the inherently improbable assumption that destruction (or sequestration) is immediate. While this modification yields space values which do not show the rapid and progressive increases seen with the original procedure, the values are erratic, and our demonstration that spaces calculated with allowance for progressive destruction, as injected minus (excreted plus destroyed)/plasma level, are more nearly constant than those of Gilman, Philips, and Koelle (5) makes the assumption of immediate destruction unnecessary.

Poulos' expression (10) for procedure (g), space equals amount excreted in a period/change in plasma level in that period, is equivalent to the original expression (8), space equals renal clearance/slope of the line obtained by plotting natural logarithm of plasma level against time, here designated as procedure (e). ${ }^{2}$ It was assumed by Newman, Bordley, and Winternitz (8) "that an equilibrium of concentration is established throughout the fluid." It is not apparent why their calculations are presumed to be valid by 25 minutes after injection, while in those of Poulos (10) a delay of 120 minutes is recommended, mannitol being used in both cases.

Procedure (f) was designed to permit use of substances whose clearance is partly extrarenal. Space equals total clearance in a period/change in natural logarithm of plasma concentration in that period (9). Obviously, only substances whose plasma concentration curves follow a straight semilog line after termination of infusion can be used; inulin is not suitable. Total clearance is obtained from the rate of calibrated infusion maintaining constant plasma level. Equilibration within the measured space is assumed to

$$
\begin{aligned}
& 2 \text { Newman (8): } \mathrm{Vc}=\frac{\mathrm{C}}{\mathrm{S}}=\frac{\mathrm{UV} / \mathrm{Pav}}{(\ln \mathrm{Pa}-\ln \mathrm{Pb}) /(\mathrm{tb}-\mathrm{ta})} \\
= & \frac{\mathrm{UV}(\mathrm{tb}-\mathrm{ta})}{\mathrm{Pa}-\mathrm{Pb}}[\text { Poulos (10)]. }
\end{aligned}
$$

persist following cessation of the calibrated infusion.

Constancy of clearance is a prerequisite for injection-extrapolation in intact subjects (3), for renal or total clearance/slope $(8,9)$, and for differential clearance (10). Any simple dilution procedure $(5,6)$ must assume maintenance of equilibration between plasma and ECF. We therefore believe that the infusion-recovery and the calibrated infusion spaces should most nearly represent some reproducible compartments of total ECF in intact subjects, and that the injectionextrapolation, or the simple dilution value at one (rat) or one and a half to two (dog) hours after injection, should give equally valid values in nephrectomized subjects. In this paper we compare in a given dog the sucrose spaces believed to best represent the truly equilibrated space with those determined by other methods. Similar comparisons were made with inulin.

\section{PROCEDURE AND METHODS}

Comparisons were made on each of three female dogs. Five-hour recoveries following a single intravenous injection of saccharide were made on dogs without anesthesia or with Pentothal Sodium; no effect of anesthesia on recovery was seen. Urine flows were elevated by water administration via stomach tube before beginning the experiment, with supplemental water doses in some experiments. Flows were 1.5 to $4 \mathrm{ml}$. per minute for the first two and a half hours or longer, since water diuresis is not affected by Pentothal Sodium. An initial dose of about $10 \mathrm{ml}$. of 2.5 per cent Pentothal Sodium intravenously was supplemented with doses of 1 to $4 \mathrm{ml}$. at about 30 minute intervals. Since urine flows were well maintained, no corrections for dead space have been made. Dogs were deprived of food but not water from the afternoon preceding the experimental day. Inuloid blank excretion in such fasted dogs is always close to $1.5 \mathrm{mg}$. per hour, and plasma inuloid levels are 11 to $15 \mathrm{mg}$. per liter, the sucrose equivalents being twice as high. Plasma inuloid blanks are 15 to 22 mg. per liter in control nephrectomized dogs at 24 hours, averaging $19 \mathrm{mg}$. Variations in postnephrectomy blank are a negligible percentage of the high 24 hour plasma levels produced in nephrectomized dogs (inulin about $1,000 \mathrm{mg}$. per liter, sucrose about 1,700 ).

Single injections of about $0.44 \mathrm{Gm}$. sucrose or 0.22 $\mathrm{Gm}$. inulin per $\mathrm{Kg}$. body weight were made from a syringe as 10 per cent sucrose in water or as 5 per cent inulin in saline, injection time being sometimes one minute and sometimes ten minutes. Residual saccharide in the beaker and syringe was determined and subtracted from the weighed amount to give the amount injected. For continuous or calibrated infusion, a weighed amount 


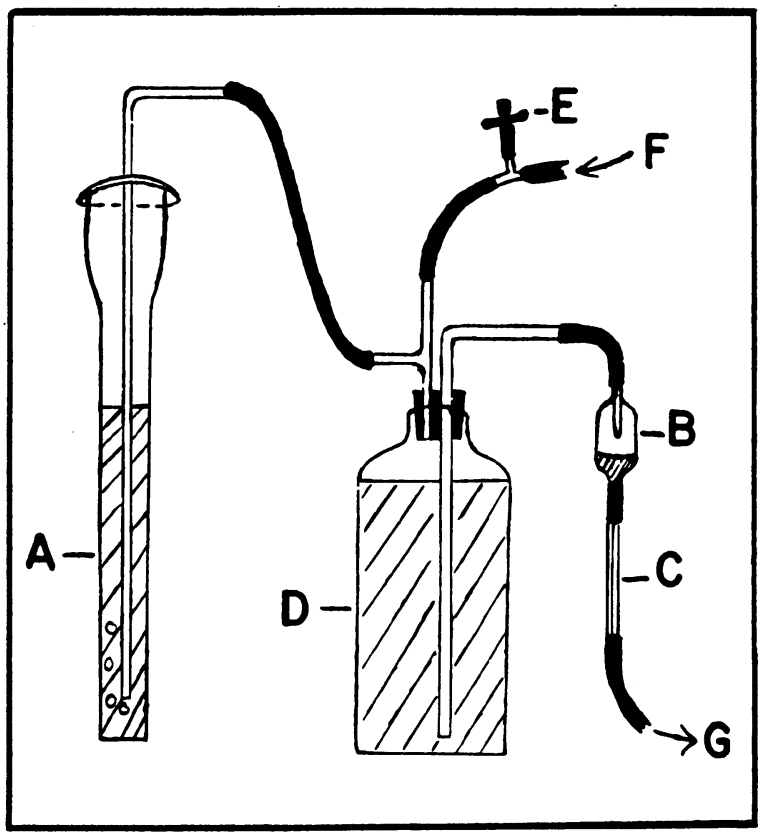

Fig. 1. Infusion Apparatus

A, mercury overflow valve; $B$, Murphy drip bulb; C, glass capillary; $\mathrm{D}$, infusion bottle; $\mathrm{E}$, clamp; $\mathrm{F}$, from air line; $G$, to vein.

of saccharide, plus sodium chloride to make the solution isotonic, were dissolved in the injection bottle. The solution was infused, with the bottle pressure maintained at about $140 \mathrm{~mm}$. $\mathrm{Hg}$ by a mercury overflow valve, at about $1.6 \mathrm{ml}$. per minute through a high resistance glass capillary inserted in the rubber tubing between the bottle and plastic tubing in the vein. A Murphy drip bulb in the injection line permitted a check on the constancy of infusion rate. The arrangement is illustrated in Figure 1. For the calibrated infusion determinations the drop rates in the bulb were calibrated against weighed amounts of solution delivered before and after the experiments. Drop size on a given day usually remained constant within plus or minus 1 per cent from the mean. Mean rate of saccharide infusion was determined as weighed amount of saccharide put into infusion flask minus residual amount determined by analysis, divided by the number of minutes. Constancy of in-

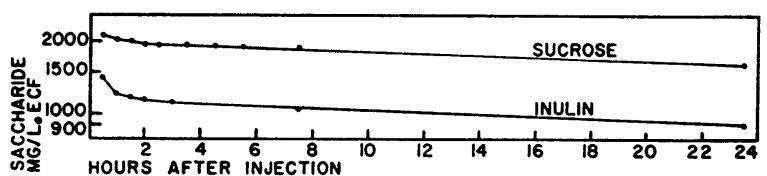

Fig. 2. Concentrations of Sucrose and Inulin in Plasma Water Following Intravenous Injection of About $0.42 \mathrm{Gm}$. Sucrose or $0.21 \mathrm{Gm}$. InUlin Per KG. Body Weight Into Nephrectomized Dogs

Each curve shows average of three dogs. fusion rate to plus or minus 2 or 3 per cent from the mean was controlled by drop counting. The rate of infusion per minute per $\mathrm{Kg}$. body weight was about $4 \mathrm{mg}$. inulin and $8 \mathrm{mg}$. sucrose. A priming injection of about $0.22 \mathrm{Gm}$. inulin or $0.44 \mathrm{Gm}$. sucrose per $\mathrm{Kg}$. body weight from a syringe preceded the continuous infusion in the infusion-recovery determinations.

For space determinations, as cited by other workers $(3,5,6,10)$, plasma levels were determined on samples drawn from a leg vein at various times after injection, with corresponding urine determinations. Venous plasma is presumed to be more nearly equilibrated with ECF than is arterial plasma. For determinations according to Gaudino, Schwartz, and Levitt (1), constancy of plasma level at about $1,000 \mathrm{mg}$. inulin and $2,000 \mathrm{mg}$. sucrose per liter was verified; this was attained at one and a half to two hours of infusion with sucrose and with inulin. For determinations according to Swan, Madisso, and Pitts (4), dogs were nephrectomized under barbital sodium and given about $0.22 \mathrm{Gm}$. inulin or $0.44 \mathrm{Gm}$. sucrose per $\mathrm{Kg}$. body weight intravenously, blood samples being obtained at various times up to 24 hours. Resultant plasma levels are seen in Figure 2.

The bladder was washed twice with water at the end of each urine period. Sucrose and inulin were determined essentially according to Schreiner (13), using zinc-sodium hydroxide plasma filtrates. We have used sucrose obtained from a grocery store. Inulin was Pfanstiehl C. P. run through a Seitz filter, precipitated from 70 per cent alcohol and dried. It contained less than 1 per cent reducing substance. Standards were made from the material injected. Kidney invertase and inulinase activities were determined on kidney homogenates incubated at $38^{\circ} \mathrm{C}$. for an hour; reducing substances after incubation were estimated on zinc-sodium hydroxide filtrates by comparison with known amounts of glucose or fructose similarly treated with qualitative Benedict's solution.

\section{RESULTS}

Recoveries of sucrose and inulin, and comparison of spaces determined according to previous workers $(1,3,4,6,10)$ are shown in Table $I$. The simple dilution space (I-E)/P (injected minus excreted/plasma water level) at zero time $(\mathrm{I} / \mathrm{Po})$ is the injection-extrapolation space (3). Simple dilution spaces (I-E)/P determined according to Lavietes, Bourdillon, and Klinghoffer (6) and Elkinton (7) rise progressively in all experiments. Simple dilution spaces $(\mathrm{R}-\mathrm{E}) / \mathrm{P}$ (recovered minus excreted/plasma water level) determined according to Gilman, Philips, and Koelle (5) are not shown in the table. They were more nearly constant than was $(\mathrm{I}-\mathrm{E}) / \mathrm{P}$, but were erratic, sometimes rising and sometimes falling. 
COMPARISON OF SPACE DETERMINATIONS

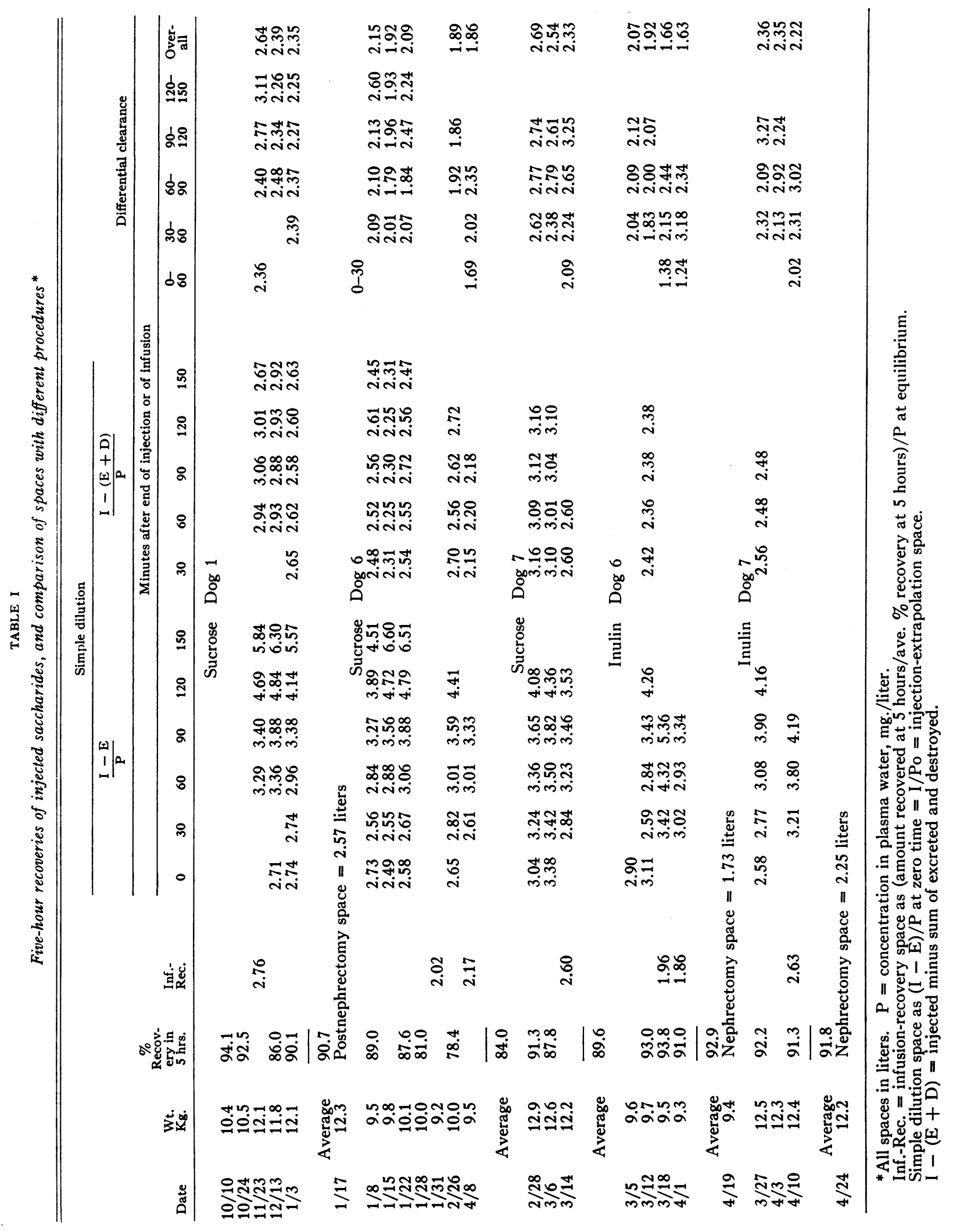


TABLE II

Sucrose spaces on Dog 1 by infusion-recovery and calibrated infusion*

\begin{tabular}{|c|c|c|c|c|c|c|}
\hline \multirow[b]{2}{*}{ Date } & \multirow[b]{2}{*}{ Wt. } & \multicolumn{4}{|c|}{$\begin{array}{c}\text { Calibrated infusion, } \\
\text { minutes }\end{array}$} & \multirow{2}{*}{$\begin{array}{l}\text { Infusion- } \\
\text { Recovery }\end{array}$} \\
\hline & & 60 & 90 & 120 & 150 & \\
\hline & Kg. & \multicolumn{4}{|c|}{ liters } & liters \\
\hline $\begin{array}{r}12 / 20 / 56 \\
1 / 10 / 57\end{array}$ & $\begin{array}{l}12.3 \\
12.2\end{array}$ & $\begin{array}{l}2.59 \\
2.36\end{array}$ & $\begin{array}{l}2.68 \\
2.53\end{array}$ & $\begin{array}{l}2.69 \\
2.63\end{array}$ & $\begin{array}{l}2.66 \\
2.69\end{array}$ & $\begin{array}{l}2.76 \\
2.58\end{array}$ \\
\hline
\end{tabular}

* See references (1) and (2).

Neither sucrose nor inulin recovery was complete at five hours. For determinations according to Gaudino, Schwartz, and Levitt (1) we have therefore taken (amount recovered at five hours)/(average per cent recovery at five hours) as the amount of available material present in the dogs at cessation of infusion. In our experience recovery is never complete, with or without anesthesia; only 0.5 to 1.5 per cent additional inulin or sucrose is recovered in the two hours following the first five hours, and only a fraction of a per cent in the next 16 hours. This is consistent with our finding that plasma levels of inulin or sucrose, after blank correction, are only 6 to $12 \mathrm{mg}$. per liter at five hours. The unrecovered amount is either destroyed or remains in cells.

Table II shows calibrated infusion, and infusion-recovery sucrose spaces without priming, on Dog 1. Tables I and II show a surprising agreement in simple dilution values on Dog 1 (sucrose only) obtained as $\mathrm{I}-(\mathrm{E}+\mathrm{D}) / \mathrm{P}$ (see below), and by injection-extrapolation as $(\mathrm{I}-\mathrm{E}) / \mathrm{P}$ at zero time, by differential clearance, by calibrated infusion, by infusion-recovery, and after nephrectomy. Even though the plasma curve was still rising at 150 minutes in the experiments of Table II (no priming), the infusionrecovery spaces agree well with that of $11 / 23$, Table I, where constant plasma level was achieved (priming).

The differential clearance spaces of Dog 1 (Table I) on 11/23 were obtained on the falling plasma curve following cessation of infusion, i.e., after equilibration. They rise progressively, as do both sucrose and inulin spaces so obtained on Dogs 6 and 7 on 4/8, 3/14, 3/18, 4/1 (except for the last period) and $4 / 10$. If the differential clearance method is sound it should give results which are at least as consistent on a falling curve following equilibration as following a single injection. This procedure following a continuous infusion is essentially equivalent to the total clearance/slope procedure (9), since the amount destroyed in a period is with inulin a very small and with sucrose a small fraction of the amount excreted in that period, and the error is not cumulative. Thus, the amount leaving the subject in a period is represented closely by the amount excreted. Schwartz (9) pointed out that inulin was not suitable, since its falling plasma curve is not a simple exponential. Therefore, our results of $3 / 18,4 / 1$ and $4 / 10$ with inulin are not surprising. We were disappointed, however, to find that the sucrose spaces of $11 / 23,4 / 8$ and $3 / 14$ following equilibration by continuous infusion were actually less consistent than those following a single injection, even though observations in the latter case began as early as 30 minutes after injection. It appears to us that the frequent consistent results with the single injection differential clearance procedure (10) may be fortuitously due to the operation of opposing errors. Our failure to get the results with sucrose which would be expected from Schwartz' analysis (9) indicates failure to maintain equilibration between plasma and ECF following cessation of infusion.

In Dogs 6 and 7 the injection-extrapolation sucrose spaces fail to show the good agreement with infusion-recovery spaces observed in Dog 1. The injection-extrapolation inulin spaces on Dog 6 are much higher than the infusion-recovery or the postnephrectomy, although in Dog 7 the agreement is good. In Dogs 6 and 7 the differential clearance sucrose spaces following a single injection agree well with the infusion-recovery, and the differential clearance inulin single injection spaces agree fairly well with infusion-recovery and postnephrectomy.

The progressive rise in simple dilution space $(\mathrm{I}-\mathrm{E}) / \mathrm{P}$ has been interpreted (5) as meaning that destruction is complete quite early after injection, and on this basis (recovered minus excreted)/plasma water level, $(R-E) / P$, was taken as a better expression. Since such immediate destruction seemed inherently improbable, we have made space calculations on the assumption that destruction is progressive. Destruction means disappearance from ECF other than 
through excretion, whether due to actual destruction in ECF or cells, or to cell entry and trapping. The method of calculating rate of destruction was as follows:

Assume that the rates of excretion and of destruction are proportional to the concentration. ${ }^{8}$ Let $\mathrm{k}=(\ln \mathrm{C}(\mathrm{o})-\ln \mathrm{C}(\mathrm{t}) / \mathrm{t}$, where $\mathrm{C}$ is concentration of particles in the fluid compartment. $\mathrm{k}=\epsilon+\delta$, where $\epsilon$ and $\delta$ are rate constants of excretion and destruction, respectively.

$$
\epsilon=\frac{\mathrm{kN}_{\epsilon}(\mathrm{t})}{\mathrm{N}(\mathrm{o})} \cdot \frac{\mathrm{C}(\mathrm{o})}{\mathrm{C}(\mathrm{o})-\mathrm{C}(\mathrm{t})},
$$

where $N_{\epsilon}(t)$ is amount excreted in time $t, N(0)$ is amount present in compartment at beginning of period; $\mathrm{C}(\mathrm{o})$ and $\mathrm{C}(\mathrm{t})$ are concentrations at beginning and end of period.

$$
\mathrm{N} \delta(\mathrm{t})=\frac{\delta}{\mathrm{k}} \cdot \mathrm{N}(\mathrm{o}) \cdot \frac{\mathrm{C}(\mathrm{o})-\mathrm{C}(\mathrm{t})}{\mathrm{C}(\mathrm{o})},
$$

where $N_{\delta}(t)$ is the amount destroyed in time t.

The sum of cumulative excretion plus destruction up to the end of a given period is subtracted from the amount injected to give the amount of diffusible material remaining at the end of that period. This value is divided by the concentration in plasma water at that time to get the space. These spaces are shown in Table I under the heading $I-(E+D) / P$. This method can be employed only if fall in concentration follows a straight semilog line rather closely. In some cases this was true only for the early part of the experiment, in which case spaces could be calculated only for that part.

Plasma concentrations of early samples obtained at short intervals after the end of a single injection of 1 or 10 minutes' duration were always above the extrapolated values of the straight semilog line on which later samples fell. Values were on the

\footnotetext{
3 This assumption is in error to the extent that equilibration between plasma and interstitial fluid fails to be complete. An error of 10 or 20 per cent here would introduce the same percentage error into amount calculated as destroyed. Since with sucrose our calculated amounts usually agreed within 10 per cent with observed amounts destroyed (see Appendix), this may be taken as indirect evidence that at about 30 minutes and thereafter, following a single injection into normal dogs, sucrose concentrations in plasma water and in pericellular water are usually not more than 10 per cent apart in cases where the falling plasma curve is following a straight semilog line.
}

line by 30 or 40 minutes, but attainment of a straight line cannot be considered as proof of equilibration, since 1.5 to 2 hours are required to reach a straight line after sucrose injection into a nephrectomized dog, and about 2 hours with inulin (Figure 2).

The rate of fall of plasma level following sucrose injection in a nephrectomized dog is considerably less than that expected from the rate of destruction evidenced by incompleteness of recovery from intact dogs. The recovery findings of Table I, together with the finding that not more than an additional 2 per cent is recovered after five hours, indicate that 10 to 15 per cent of the injected sucrose are destroyed at five hours. However, the plasma level five hours after injection in the nephrectomized dog is only 3.5 per cent lower than the zero time extrapolated equilibrium value (Figure 2), and this rate of fall persists for 24 hours. We have designated the rate of change per minute in the natural logarithm of plasma concentration as $\mathrm{k} ; \epsilon$ is that component of $\mathrm{k}$ due to excretion and $\delta$ that due to destruction. In nephrectomized dogs plasma sucrose level falls about 0.014 per cent per minute (Figure 2). In such dogs, $\delta=k=0.00014$, i.e., 0.014 per cent of the sucrose in a nephrectomized dog is destroyed per minute, and this value was quite constant in each of three dogs. Sucrose $\delta$ values in three intact dogs $(\mathrm{k}-\epsilon)$ range from 0.001 to 0.0022 , with a mean of 0.00172 , i.e., 0.172 per cent of the sucrose in an intact dog is destroyed per minute, or about 12 times the rate in the nephrectomized dog. This discrepancy is far greater than can be accounted for by any errors of assumption, calculation or experiment. This indicates that a major part of the destruction depends on the presence of the kidneys.

To test this point, 2 per cent dog kidney homogenates in 10 per cent sucrose were incubated for one hour at $38^{\circ} \mathrm{C}$., and zinc-sodium hydroxide filtrates tested for reducing substances. Blank homogenates showed essentially no reduction, while sucrose homogenates showed 5 per cent inversion of sucrose. Muscle homogenates showed no invertase activity. While quantitative comparison of the $\delta$ value $(0.00086)$ obtained under these conditions with that calculated for intact dogs $(0.00172)$ cannot be made, the observations show a high invertase activity of kidney tissue, 
and afford a plausible explanation for the much more rapid rate of sucrose destruction in the intact than in the nephrectomized dog. The glucose and fructose resulting from the inversion, which is assumed to take place in the tubular cells, presumably enter the blood stream, with subsequent tissue utilization of the glucose and of part of the fructose, and excretion of the unutilized fructose.

Under comparable conditions inulin was hydrolyzed by kidney homogenates to only about 15 per cent the extent observed with sucrose. Calculation of $\delta$ values for inulin has not been possible in most excretion experiments in intact dogs because of failure of the falling plasma curve to follow a straight semilog line. Where such calculations have been made they are in considerably greater error than with sucrose because the falling inulin curves always show some deviation from a straight semilog line and because rate of destruction is so low compared with rate of excretion. We can only say that $\delta$ values calculated for inulin are considerably lower than for sucrose, which is consistent with the finding that hydrolysis of inulin by kidney homogenates is considerably less than that of sucrose.

\section{DISCUSSION}

Our observed recoveries of sucrose are based on the resorcinol reaction after acid hydrolysis. Under the conditions employed (13), 99 per cent of the color of hydrolyzed sucrose is due to fructose. Since part of the resorcinol-reactive material in our urines is fructose, the actual sucrose recoveries are lower than given in Table I. Thus, Dog 6 on 1/28, after injection of $4.4 \mathrm{Gm}$. of sucrose, excreted 2,450 mg. of "sucrose" (resorcinol reaction) in the first hour and $826 \mathrm{mg}$. in the second hour. The urines were free from glucose by test with Clinistix Reagent strips (Ames Co., Inc., Elkhart, Indiana). The first hour's urine contained $100 \mathrm{mg}$. of the reducing substance, fructose. The second hour's urine contained $25 \mathrm{mg}$. of fructose. While $3,276 \mathrm{mg}$. of the injected sucrose appeared as resorcinol-reactive material in the first two hours, this consisted of $125 \mathrm{mg}$. fructose with the chromogenic activity of $250 \mathrm{mg}$. sucrose, and $3,026 \mathrm{mg}$. sucrose. Thus, only 92 per cent of the resorcinol-reactive material was sucrose, and if the experiment shows 90 per cent recovery of resorcinol-reaction material in five hours, only 83 per cent is unhydrolyzed sucrose. This example is a typical result. Our findings agree with those of Power and Keith (14). Incompleteness of sucrose recovery need not invalidate its use in space measurements, since its rate of destruction can be calculated and appropriate allowance made. Nor does the finding that a few per cent of the material determined as sucrose in the urine is fructose invalidate the space findings. No error is introduced into the excretion findings, and whatever small amounts of free fructose may exist in ECF must have about the same volume of distribution as sucrose. It is true that these changes make any simple method of calculating sucrose space in the dog invalid, but if the reports of others that sucrose is completely recovered from man are correct, these complications of calculations would not occur in experiments on man.

We were encouraged by the findings on Dog 1 to believe that any of the methods, except (I $\mathrm{E}) / \mathrm{P}$, would give valid sucrose spaces. The findings on Dogs 6 and 7 do not support this optimism. Each procedure is discussed below.

\section{Simple dilution space, $(I-E) / P$}

A progressive rise is seen in all experiments with both sucrose and inulin. This is largely because the dividend is erroneously high by a progressively increasing percentage when destruction is not allowed for. For reasons stated above, we do not consider $(\mathrm{R}-\mathrm{E}) / \mathrm{P}$ an adequate formula.

\section{Simple dilution space, corrected for destruction, $I-(E+D) / P$}

When allowance is made for material destroyed (or trapped), as well as for that excreted, dilution spaces remain reasonably constant on a given day, but in Dogs 6 and 7 are usually considerably higher than the infusion-recovery or postnephrectomy space. Since the assumption of progressive destruction is more probable than that of immediate destruction, and since spaces calculated on the former assumption are more nearly constant than those calculated on the latter, there seems to be no reason to retain the concept of immediate destruction. Nevertheless, we cannot 
accept the $\mathrm{I}-(\mathrm{E}+\mathrm{D}) / \mathrm{P}$ spaces without reservation, since we doubt that equilibration is ever attained following a single injection. It may seem illogical to lack confidence in results obtained by a single-injection procedure even though they may agree with those obtained by the infusionrecovery, calibrated infusion, and postnephrectomy procedures. Our reasons are two. First, in our hands such agreement is not obtained consistently. Second, we believe the latter three methods are on a sounder, although admittedly not unassailable, theoretical basis.

Walser, Seldin, and Grollman (15), using radioactive inorganic sulfate, modified the injectionextrapolation procedure by dividing $\mathrm{I}-\mathrm{E}$ at 18 minutes in the dog, or 25 to 30 minutes in man, by concentration in interstitial water to get simple dilution spaces at those times. Demonstration that falling plasma curves become simple exponentials at such times is taken as evidence of equilibration between plasma and "functional extracellular fluid." 4

The findings on the nephrectomized dog afford the strongest argument against such early equilibration. If such equilibration were in fact attained at about 18 minutes following a single rapid injection of radiosulfate in the intact dog, the initially rapidly falling curve following a single injection in the nephrectomized dog should "break" to the more slowly falling straight semilog line at about that time, whereas the change does not occur until one and a half to two hours, about the same time as for mannitol, inulin, sucrose and thiosulfate (4). It might be argued that the more rapidly diffusing substances equilibrate rapidly with the "functional" extracellular fluid, and that the last one to one and a half hours required to reach the straight semilog line is the time during which the less easily accessible connective tissue and "transcellular" compartments are being penetrated. If this were true, the radiosulfate and thiosulfate curves should have more nearly approached the extrapolated straight line at 30 minutes than should inulin, but there is no evidence in the findings of Swan, Madisso, and Pitts

\footnotetext{
4 Since rate of disappearance from plasma through cell entry and/or metabolism is about as great as that through excretion, simple dilution spaces as $(I-E) / P$ show the expected rapid and progressive increase with time.
}

(4) that this is happening, although it is true that in our Figure 2 the sucrose curve is closer to the line at 30 minutes than is inulin. We can only say that while radiosulfate as employed by Walser, Seldin, and Grollman (15) may measure pericellular or "functional" ECF, the infusion-recovery, calibrated infusion and postnephrectomy procedures seem to us at present to be on a sounder theoretical basis.

\section{Amount injected/plasma level extrapolated to zero time, $I / P o$, injection-extrapolation}

With Dogs 6 and 7 this space, both sucrose and inulin are considerably higher than the infusionrecovery or the postnephrectomy. In many experiments no value can be obtained with this method because of uncertainty of slope even after the points are falling fairly closely on a straight semilog line. The finding that even with the best straight lines these values are higher than infusion-recovery or postnephrectomy spaces is further evidence that equilibration does not occur. Further difficulties in this method are discussed by Chesley and Lenobel (16).

Evidence that equilibration is not attained following a single injection may be summarized here. First, with both sucrose and inulin the injectionextrapolation space, when obtainable, is higher than the infusion-recovery or the postnephrectomy space. Second, simple dilution sucrose spaces after allowing for destruction, even though constant, are usually higher than infusion-recovery or postnephrectomy. Third, a straight semilog line of falling plasma sucrose level is inadequate evidence of equilibration, because the straight line, when seen, is achieved in 30 or 40 minutes following a single injection in the intact dog, while 1.5 to 2 hours are required in the nephrectomized dog. Fourth, Schachter, Freinkel, and Schwartz (17) have shown that equilibration of inulin is not achieved following a single injection in dog or man.

Failure of ourselves and others to get consistent agreement of space determinations by injection-extrapolation or simple dilution with values obtained by the infusion-recovery or postnephrectomy procedures, even when in the simple dilution procedure correction for destruction is made and constant successive values may be ob- 
tained, is interpreted as indicating failure of equilibration with the former procedures even when a more rapidly diffusing substance than inulin, i.e., sucrose, is used. None of the considerations of this or the preceding paragraph constitutes proof that a satisfactorily close approach to equilibration cannot occur following a single injection of a still more rapidly diffusing substance, such as radiosulfate. We cannot dismiss the possibility that such a procedure (15) may measure pericellular plus some fraction of connective tissue fluid, at least in normal subjects. More repeated determinations on the same subjects are needed to establish degree of consistency.

Amount excreted in a period/change in plasma level in that period-Differential clearance

Poulos (10) has proposed an amount excreted in a period/change in plasma level in that period as a measure of volume distribution. This procedure does not demand that equilibration between plasma and interstitial fluid be achieved following a single injection, but does demand a constant difference between plasma and interstitial fluid levels. He postulated that the plasma and interstitial fluid curves do in fact become parallel at one and a half to two hours after a single injection. Even though the absolute values of differences between the curves become small as the two levels themselves become small, there is no theoretical reason to believe that the difference becomes a smaller percentage of the absolute values. Direct evidence, similar to that of Schachter, Freinkel, and Schwartz (17), is difficult or impossible to obtain on working with the low plasma levels existing late after a single injection.

\section{Infusion-recovery procedure}

We have not obtained complete recoveries following a single injection of either sucrose or inulin from the dog in 24 hours. This is true without anesthesia, or with the dog under Pentothal ${ }^{\circledR}$ Sodium for the first 5 or 6 hours. Recoveries of sucrose (resorcinol-reactive material in urine) at 5 hours averaged $90.7,84.0$ and 89.6 per cent in these three dogs; 98 to 99 per cent of that excreted in 24 hours have been excreted at 5 hours, 1 to 1.5 per cent more in the period from 5 to 7 hours, and none or a few tenths of a per cent between 7 and 24 hours. Recoveries of inulin at 5 hours averaged 92.9 and 91.8 per cent in Dogs 6 and 7; 99.5 per cent of that excreted in 24 hours has been excreted at 5 hours, and the remainder in the period from 5 to 7 hours. We have therefore taken amount excreted in five hours following cessation of infusion/average percentage recovery of a single injection in five hours as the diffusible or available amount remaining in the dog at end of infusion. This amount divided by the equilibrium concentration in plasma water gives the space. We consider this, together with the calibrated infusion (2) and the postnephrectomy values, as the best measures now available. This view is not negated by our finding on nephrectomized rats (12) that whole body inulin and sucrose spaces rise with time, following a straight semilog line rather closely for many hours; determinations were not made at short enough early intervals to establish the "break" in falling plasma levels. We are now convinced, on the basis of our and others' findings with the calibrated infusion and postnephrectomy procedures, that in the dog equilibration between plasma and interstitial (plus some fraction of connective tissue) fluid is achieved with both sucrose and inulin at two hours of a constant infusion preceded by a priming injection. Whatever cell entry, with destruction or trapping, has taken place within this time does not affect the result, since it is not seen in the recovered material.

\section{Calibrated infusion procedure (2)}

We have used this procedure, with sucrose only, in one dog (Table II). It agreed well with the infusion-recovery and postnephrectomy values. The practical handicap to its use is the necessarily high degree of precision in infusion rate. If destruction or trapping of the injected material is occurring, allowance must be made for this to get the best results, but we do not see how to do this with a plasma curve of the type seen in these experiments.

Although plasma levels are still rising slowly at two and a half hours of calibrated infusion (no priming), infusion-recovery values obtained after cessation of such infusion agree with those obtained following establishment of constant plasma 
levels (priming). This finding may be added to the constancy of successive calibrated infusion spaces as further evidence that almost complete equilibration occurs at or before two hours with either method. Practical achievement of equilibration can occur because the percentage rate of rise of plasma after one and a half hours is low, a quite different situation from the high percentage rate of fall after a single injection or after termination of an infusion.

\section{Postnephrectomy space}

Our rate of fall of plasma levels following single injection into the nephrectomized dog is about 0.014 per cent per minute for sucrose and 0.016 per cent per minute for inulin for the period between 3 and 24 hours $(\mathrm{k}=\delta=0.00014$ and $0.00016)$. These values are lower than those of Swan, Madisso, and Pitts (4), who found $\mathrm{k}$ from 0.00025 to 0.0004 for sucrose, and 0.00036 to 0.00056 for inulin. Spaces are calculated as amount injected/concentration in plasma water extrapolated to zero time.

Our inulin k value agrees well with the 0.00012 of Finkenstaedt, O'Meara, and Merrill (18) and the 0.00014 of Bálint and Forgács (19), calculated from their data on nephrectomized dogs. Mulrow, Oestreich, and Swan's Figure 1 gives a k value of 0.00021 for sucrose (20). We have reported data $(11,12)$ yielding $\mathrm{k}$ values of about 0.0006 for inulin and 0.0005 for sucrose in nephrectomized rats, i.e., both inulin and sucrose enter cells much more rapidly in nephrectomized rats than in nephrectomized dogs. This may mean greater activity of macrophages toward inulin in rats than in dogs. These $\mathrm{k}$ values are for whole rats; there is great variability among different tissues $(11,12)$.

A few words must be said against the possibility that these are abnormal results, i.e., that cellular permeability to these saccharides is increased after nephrectomy. In the rat we have shown (12) that the rate of fall of plasma inulin level and of rise in calculated space ( $k$ value) is not different in rats nephrectomized 24 hours before injection from that in rats nephrectomized at time of injection. If cellular permeability to inulin is increased after nephrectomy, the increase should be greater the longer the animal has been nephrectomized. We think it probable that cell entry of inulin is largely through ingestion by macrophages, since $k$ values are highest in skin, liver and spleen, tissues which are rich in macrophages; this view is supported by Jancsó's histochemical demonstration of inulin in such cells in connective tissue and liver of mice (as cited in Reference 19). The maintenance of a straight semilog line of falling plasma level in nephrectomized subjects in itself speaks against increasing cell permeability, as well as a against (a) appreciable continued diffusion (after the first hour in the rat and second hour in the dog) into less easily accessible extracellular compartments, and (b) actual increase in volume of ECF. Corresponding and additional evidence is presented that in the dog cellular permeability to inulin is not increased at several days after nephrectomy (19), or to sucrose at 30 hours (20).

Infusion-recovery spaces are somewhat higher than corresponding postnephrectomy spaces. This is largely accounted for by the positive water load existing at cessation of infusion. Intake up to cessation of infusion exceeded urine output by 0.09 to 0.25 liters. When correction is made for this, the infusion-recovery values are: 2.67 liters for Dog 1 sucrose on $11 / 23 ; 1.78$ and 1.62 liters for Dog 6 inulin on $3 / 18$ and $4 / 1$; and 2.38 liters for Dog 7 inulin on $4 / 10$. These agree well with the corresponding postnephrectomy spaces (Table I).

\section{SUMMARY}

Comparisons of various procedures for determining sucrose and inulin spaces in dogs have been made. The calibrated infusion, constant infusion to equilibration, and postnephrectomy values agree and are considered to be the most reliable. No single injection method in intact subjects is considered to be acceptable without reservation, even though values agreeing with the above methods are often obtained. The progressive rise in simple dilution space following a single injection, or cessation of constant infusion, of a substance not completely recoverable is ascribed to progressive rather than to immediate destruction or trapping. Expressions are given for calculating such destruction. Added evidence that diffusion equilibrium is achieved within two hours of constant infusion preceded by a priming injection 
is afforded by the finding that infusion-recovery spaces so obtained agree with those obtained following cessation of a two hour infusion not preceded by priming, even though in the latter situation the plasma level is still rising slowly at two hours.

Since recoveries following injection of known amounts were never complete with either sucrose or inulin, we have taken the amount recovered in five hours/average per cent recovery in five hours as the value to be divided by the plasma water level at equilibrium to give the infusion-recovery space. This is believed to be the most practical valid method now available for use in intact subjects.

The major part of the destruction of sucrose following intravenous injection in the dog is made possible through inversion in the kidneys.

\section{APPENDIX}

Assume that the concentration, $\mathrm{C}(\mathrm{t})$, of sucrose in the fluid compartment is falling due to two processes only (excretion and destruction) and that the rate of each is proportional to $\mathrm{C}(\mathrm{t})$. These assumptions lead to the equations:

$$
\begin{aligned}
& \frac{\mathrm{dN}_{\epsilon}(\mathrm{t})}{\mathrm{dt}}=\mathrm{EC}(\mathrm{t})=\frac{\mathrm{E}}{\mathrm{V}} \mathrm{N}(\mathrm{t})=\epsilon \mathrm{N}(\mathrm{t}), \\
& \frac{\mathrm{dN}_{\delta}(\mathrm{t})}{\mathrm{dt}}=\mathrm{DC}(\mathrm{t})=\frac{\mathrm{D}}{\mathrm{V}} \mathrm{N}(\mathrm{t})=\delta \mathrm{N}(\mathrm{t}),
\end{aligned}
$$

where $\mathrm{V}$ is the (constant) volume of the fluid compartment, and $N(t)$ is amount of sucrose it contains at time $t$. Since only these processes are occurring, the rate of decrease of sucrose in the fluid compartment is the sum of these rates and we have

(3) $-\frac{\mathrm{dN}(\mathrm{t})}{\mathrm{dt}}=\mathrm{kN}(\mathrm{t})=\frac{\mathrm{dN}_{\epsilon}(\mathrm{t})}{\mathrm{dt}}+\frac{\mathrm{dN}_{\delta}(\mathrm{t})}{\mathrm{dt}}=(\epsilon+\delta) \mathrm{N}(\mathrm{t})$,

and $\epsilon+\delta=\mathrm{k}$ as defined in text.

To determine $\epsilon$, we multiply Equation (1) by $\mathrm{dt}$ and integrate over time from 0 to $t$.

$$
\int_{0}^{t} d N_{\epsilon}(t)=\int_{0}^{t} \epsilon N(t) d t .
$$

The left side becomes $N_{\epsilon}(t)$, which is the amount of sucrose excreted up to time $t$, since $\mathrm{N}_{\epsilon}(0)=0$. Also $\mathrm{N}(\mathrm{t})=$ $N(0) e^{-k t}$ since $N(t)$ decreases exponentially with rate constant $\mathrm{k}$.

$$
\begin{aligned}
& N_{\epsilon}(t)=\int_{0}^{t} \epsilon N(0) e^{-k t} d t . \\
& \left.N_{\epsilon}(t)=-N(0) \frac{\epsilon}{k} e^{-k t}\right]_{0}^{t} \\
& N_{\epsilon}(t)=N(0) \frac{\epsilon}{k}\left(1-e^{-k t}\right) .
\end{aligned}
$$

Using the fact that $\frac{C(t)}{C(0)}=e^{-k t}$ and rearranging, we have

$$
\epsilon=k \frac{N_{\epsilon}(t)}{N(o)} \cdot \frac{C(o)}{C(o)-C(t)} \text {. }
$$

$\epsilon$ can be determined from this equation if the amount and concentration of sucrose in the fluid compartment (giving $\mathrm{N}(\mathrm{o}), \mathrm{C}(\mathrm{o}), \mathrm{C}(\mathrm{t})$ and $\mathrm{k}$ ) and the amount of sucrose excreted $\mathrm{N}_{\epsilon}(\mathrm{t})$ are determined at two or more different times. When $\mathrm{k}$ and $\epsilon$ are known, $\delta$ can be determined from $\delta=\mathrm{k}-\epsilon$. When $\delta$ is known, the number of particles destroyed at any time $t$ can be obtained from

$$
\mathrm{N}_{\delta}(\mathrm{t})=\frac{\delta}{\mathrm{k}} \mathrm{N}(\mathrm{o}) \frac{\mathrm{C}(\mathrm{o})-\mathrm{C}(\mathrm{t})}{\mathrm{C}(\mathrm{o})},
$$

which is derived as was Equation (7).

These expressions can be employed only during such time as the falling plasma level follows a straight semilog line, which is not attained until the end of the first urine period of 30 or 40 minutes' duration. We have, therefore, calculated $\epsilon$ from the beginning of the second urine period through such time as the line remains straight. For this calculation take $\mathrm{C}(\mathrm{o})$ as concentration at beginning of second period and $\mathrm{N}(\mathrm{o})$ as amount injected minus amount excreted in first period, i.e., for this first calculation of $\epsilon$, destruction in first period is neglected. This first approximation of $\epsilon$ is subtracted from $\mathrm{k}$ to get $\delta$, and, using this value of $\delta$, the amount destroyed in the first period is calculated as follows:

Mean interstitial fluid level during first period (C) is assumed to be one-half of plasma level extrapolated to zero time. For calculating amount destroyed in first period, $\mathrm{N}_{\delta}(\mathrm{t})=\frac{\delta}{\mathrm{k}} \cdot \mathrm{N}(\mathrm{o}) \cdot \frac{\mathrm{C}(\mathrm{o})-\mathrm{C}(\mathrm{t})}{\mathrm{C}(\mathrm{o})}$ cannot be used, since $\mathrm{C}(\mathrm{o})$ (here taken as concentration in interstitial fluid at beginning of first period) is not known, and since change in concentration does not follow a straight semilog line during first period. Instead, take $N_{\delta}(t)=\delta \underline{C V t}$, where $\mathrm{V}$ is volume of interstitial fluid (taken as infusion-recovery space minus assumed plasma volume), and $t$ is duration of first period in minutes.

This first approximation of $\mathrm{N}_{\delta}(\mathrm{t})$ is subtracted from original $N(0)$, and a second value for $\epsilon$ is calculated, using the new $N(0)$. Subtracting the second $\epsilon$ from $k$ gives the second approximation of $\delta$. Using this $\delta$, a second approximation of amount destroyed in first period is obtained. This process is continued until values of $\epsilon$ obtained in consecutive calculations agree closely. These values oscillate decrementally about a limit which is closely approached after four to eight steps; the mean of the last two values is used.

For calculation of amount destroyed in periods after the first, the expression $\frac{\delta}{\mathrm{k}} \cdot \mathrm{N}(\mathrm{o}) \cdot \frac{\mathrm{C}(\mathrm{o})-\mathrm{C}(\mathrm{t})}{\mathrm{C}(\mathrm{o})}$ is used, where $\mathrm{N}(\mathrm{o})$ is amount remaining, i.e., injected minus (excreted plus destroyed), at beginning of period, and $\mathrm{C}(\mathrm{o})$ and $\mathrm{C}(\mathrm{t})$ are concentrations in plasma water at beginning and end of period. We are indebted to Dr. William Sleator, Jr. of this department for the above treatment. 
The amounts of sucrose so calculated as being destroyed in the first five hours usually agreed within 10 per cent with the amounts which failed to be recovered in five hours; the maximum discrepancy was 20 per cent. With inulin the percentage discrepancies were greater, ranging from 10 to 33 per cent of the 6 to 8 per cent which failed to be recovered.

Our sucrose values of $\delta$ (change in the natural logarithm of $\mathrm{C}$ per minute due to destruction) for intact dogs average 0.00172 and for nephrectomized dogs 0.00014 , giving extrarenal clearances of about $21 \mathrm{ml}$. per $\mathrm{Kg}$. per hour for intact and 1.8 for nephrectomized dogs.

\section{REFERENCES}

1. Gaudino, M., Schwartz, I. L., and Levitt, M. F., Inulin volume of distribution as a measure of extracellular fluid in dog and man. Proc. Soc. Exper. Biol. \& Med., 1948, 68, 507.

2. Deane, N., Schreiner, G. E., and Robertson, J. S., The velocity of distribution of sucrose between plasma and interstitial fluid, with reference to the use of sucrose for the measurement of extracellular fluid in man. J. Clin. Invest., 1951, 30, 1463.

3. Cardozo, R. H., and Edelman, I. S., The volume of distribution of sodium thiosulfate as a measure of extracellular fluid space. J. Clin. Invest., 1952, 31, 280.

4. Swan, R. C., Madisso, H., and Pitts, R. F., Measurement of extracellular fluid volume in nephrectomized dogs. J. Clin. Invest., 1954, 33, 1447.

5. Gilman, A., Philips, F. S., and Koelle, E. S., The renal clearance of thiosulfate with observations on its volume distribution. Am. J. Physiol., 1946, $146,348$.

6. Lavietes, P. H., Bourdillon, J., and Klinghoffer, K. A. The volume of the extracellular fluids of the body. J. Clin. Invest., 1936, 15, 261.

7. Elkinton, J. R., Volume of distribution of mannitol as a measure of the volume of extracellular fluid, with a study of the mannitol method. J. Clin. Invest., 1947, 26, 1088.

8. Newman, E. V., Bordley, J., III, and Winternitz, J., The interrelationships of glomerular filtration rate (mannitol clearance), extracellular fluid volume, surface area of the body, and plasma concentra- tion of mannitol. Bull. Johns Hopkins Hosp., 1944, 75, 253.

9. Schwartz, I. L., Measurement of extracellular fluid by means of a constant infusion technique without collection of urine. Am. J. Physiol., 1950, 160, 526.

10. Poulos, P. P., A constant-change (single injection) method for the estimation of the volume of distribution of substances in body fluid compartments. J. Clin. Invest., 1956, 35, 921.

11. White, H. L., and Rolf, D., Inulin space as a function of equilibration time. Am. J. Physiol., 1956, $185,152$.

12. White, H. L., and Rolf, D., Whole body and tissue inulin and sucrose spaces in the rat. Am. J. Physiol., 1957, 188, 151.

13. Schreiner, G. E., Determination of inulin by means of resorcinol. Proc. Soc. Exper. Biol. \& Med., 1950, 74, 117.

14. Power, M. H., and Keith, N. M., Experiments on the distribution and renal excretion of sucrose injected intravenously in dogs (abstract). J. Biol. Chem., 1936, 114, 1xxx.

15. Walser, M., Seldin, D. W., and Grollman, A., An evaluation of radiosulfate for the determination of the volume of extracellular fluid in man and dogs. J. Clin. Invest., 1953, 32, 299.

16. Chesley, L. C., and Lenobel, A., An evaluation of the single injection thiosulfate method for the measurement of extracellular water. J. Clin. Invest., $1957,36,327$.

17. Schachter, D., Freinkel, N., and Schwartz, I. L., Movement of inulin between plasma and interstitial fluid. Am. J. Physiol., 1950, 160, 532.

18. Finkenstaedt, J. T., O'Meara, M. P., and Merrill, J. P., Observations on the volume of distribution of inulin in anuric subjects. J. Clin. Invest., 1953, 32, 209.

19. Bálint, P., and Forgács, I., The apparent expansion of the inulin space in the nephrectomized dog. Experientia, 1956, 12, 431.

20. Mulrow, P. J., Oestreich, H. M., and Swan, R. C., Measurement of extracellular fluid volume of nephrectomized dogs with mannitol, sucrose, thiosulfate and radiosulfate. Am. J. Physiol., 1956, $185,179$.

\section{SPECIAL NOTICE TO SUBSCRIBERS}

Post Offices will no longer forward the Journal when you move.

Please notify The Journal of Clinical Investigation, Business Office, 333 Cedar Street, New Haven 11, Conn. at once when you have a change of address, and do not omit the zone number if there is one. 